\title{
HEAT TRANSFER IN SOUND ASSISTED FLUIDIZED BED OF FINE POWDERS : A REVIEW
}

\author{
Sonal K. Gaikwad ${ }^{1^{*}}$, Uday S. Wankhede ${ }^{2}$

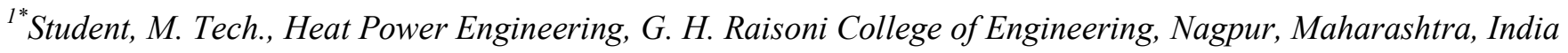 \\ skg2825@gmail.com \\ ${ }^{2}$ Professor, Department of Mechanical Engineering, G. H. Raisoni College of Engineering, Nagpur, Maharashtra, \\ India \\ udaywankhede.ghrce@raisoni.net
}

\begin{abstract}
Nanoparticles have a rare quality of very small size and a large surface area per unit mass. These are most advantageously used in many applications with their fluidization process. In such particles, for better fluidization process together with the conventional gas fluidization technique some additional forces were studied by many authors. One of them is application of sound waves. The presence of sound waves causes the decrease in the characteristic minimum fluidization velocity with increase in the heat transfer rate from heating element to very small sized particles of fluidized bed. The brief information about nano powders, fluidized bed and sound assisted fluidization process are given in the present article. Similarly, the heat transfer phenomenon in fluidized bed, the effect of sound field on fluidization of powder in presence of sound field, the measurement techniques in fluidized bed and design methods of heat transfer in fluidized bed are also presented.
\end{abstract}

Keyword: Nano Powders, Sound Field, Fluidization, Heat Transfer.

\section{INTRODUCTION}

Fluidized bed of nanoparticlesis one of the importantpart of nano technology. The bed gives advantageous outcomes as increased heat and mass transfer rates, ability to deal with a different types of particles and controlled uniform temperature values [1] and are mainly used in the various large scale industries [1,2]. In case of application of this part, essential thing is to disperse the particles and the dispersion is carried out by gas fluidization process. It becomes tough to scatter the nano particles with the technique of gas fluidization only as these particles are having large intermolecular forces $[1,2]$. Thus, the fluidized bed of nano powder shows difficulty in the simultaneous process with gas fluidization only [3,5]. Researchers studied for some external forces given to this system for effective fluidization quality of powders. Sound field shows capability to disturb all clusters $[10,11,14]$ and decrease in the velocity of minimum fluidization $[3,5,10,13,22]$, bubble free fluid-like behaviour is obtained [11]. The sound energy results for continues vibrations, replaces particle without channeling nature of the bed. Small agglomerates move upward in the column where the movement of these agglomerates occur on the basis of density difference till bed gets reached to the dynamic equilibrium stage [15,22]. Like this, sound assisted fluidized bed of nano powders improves the quality of fluidization process [6] and results more turbulence in the bed and sufficient degree of homogeneity [12]. In case of more heat transfer coefficient in this fluidized bed, quick movement of the particles is necessary and hence for this purpose, gas velocity is made to increase with required contact time of them [4,21].

\subsection{Nanoparticles}

Nanoparticles are having size below 100nm and shows advantage in industrial applications like in pharmaceutical companies for drugs, cosmetics, in production of catalysts, plastics, biomedical, food, and micromechanical systems, etc [1]. Also, they are applicable in the manufacturing of semiconductors, sunscreens and storage of hydrogen [25].

The powders are grouped by $\mathrm{D}$. Geldart, according to the sizes and the densities. These were found in four groups as; A: Aeratable $(20-100 \mu \mathrm{m})$; B: Sand like $(40-500 \mu \mathrm{m})$; C: Cohesive $(20-30 \mu \mathrm{m})$ and D: Spoutable (above $600 \mu \mathrm{m}$ ). Based on the physical property, nano particle indicates Geldart group C [1]. These particles have large forces of attraction in between them and are very complicated to separate out easily with conventional gas fluidization process [4]. The additional force, hence, is required for nano powders to acquire effective applications.

\subsection{Fluidized bed}

Fluidized bed is a collection of solid particles, fluidized with the use of compressed gas. The main advantage of this is to supply oxygen for combustion in adequate quantity together with better mixing, operative chemical reactions, for more heat and mass transfer, for coating and granulation processes. It is the process of suspension of the particles in the direction of gas flow with a velocity at which drag force exerted by the gas becomes exactly equal to the gravitational force [2].

They shows ability to fulfill the requirement of effective heat and mass transfer and unvarying temperature range 
within the bed and lower pressure drops, hence these are widely applied for heat recovery processes[4,5,25]. In case of fluidized bed of very fine particles, proper fluidization with application of conventional compressed gas technique only is unable to obtain due to the presence of large intermolecular forces. For proper process some external assisting methods are required to use and these are as: (1) sound assisted fluidization; (2) application of mechanical vibrations; (3) electro fluidization; (4) magnetically assisted fluidization; (5) application of centrifugal field; (6) use of micro jets as secondary flow through bed; (6) addition of foreign material particles [1,2].

\begin{tabular}{|ll|}
\hline \multicolumn{2}{|l|}{ Nomenclature } \\
$\mathrm{dp}$ & particle size, $\mu \mathrm{m}$ \\
$\mathrm{f}$ & frequency of sound, $\mathrm{Hz}$ \\
$\mathrm{Gs}$ & solids circulation rate, $\mathrm{kg} / \mathrm{m}^{2} \mathrm{~s} \mathrm{H}$ bed height, $\mathrm{m}$ \\
$\mathrm{h}$ & heat transfer coefficient, $\mathrm{W} / \mathrm{m}^{2} \mathrm{~K}$ \\
$\mathrm{r} / \mathrm{R}$ & radial ratio \\
$\mathrm{SPL}$ & sound pressure level, $\mathrm{dB}$ \\
$\mathrm{T}$ & temperature, ${ }^{\circ} \mathrm{C}$ \\
$\mathrm{Ug}$ & velocity of fluidizing gas, $\mathrm{m} / \mathrm{s}$ \\
$\mathrm{Umf}$ & minimum fluidization velocity \\
\hline
\end{tabular}

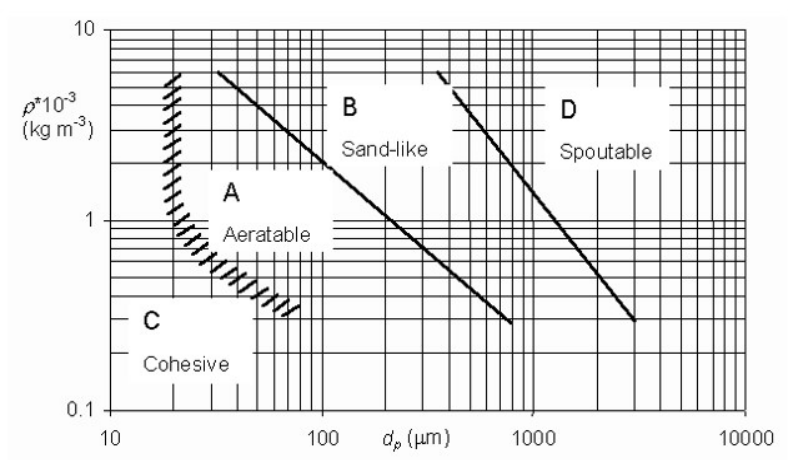

Figure 1: Geldart classification of particles [27].

\section{LITERATURE SURVEY}

\subsection{Sound Assisted Fluidization}

As discussed previously, Geldart $\mathrm{C}$ particle are much complicated to fluidize with conventional gas fluidization process only. Sound shows capability of penetrating the bed of fine powders and in presence of an external force as sound field plays an important role for decreasing the velocity of minimum fluidization, removal of channeling in the bed and causes the relative motion of larger and smaller aggregates inside the column of bed [22]. When adequate frequency of sound and SPL is given, the breaking of large agglomerates occurs and bed collapses suddenly $[10,16]$.

The effect of acoustic wave frequencies on velocity of minimum fluidization of fluidized bed was investigated by Escudero et al. [5]. The analysis was done on glass bead material of various sizes $(212-600 \mu \mathrm{m})$ with different bed to height ratio. They resulted that though the Umf decreases with increase in the sound frequency, after a particular frequency increase in that velocity is obtained. The bed pressure drop was obtained upto $150 \mathrm{~Hz}$ and Umf as a function of bed height, in other words, when H/D ratio was allowed to increase, the Umf also gets changed at constant frequency.

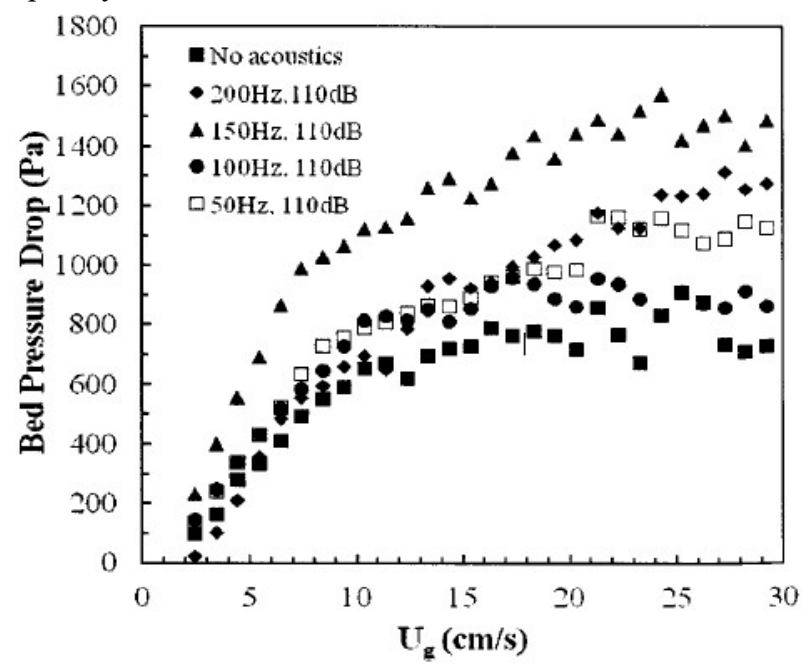

Figure 2: Bed pressure drop vs velocity of superficial gas for $500-600 \mu \mathrm{m}$ glass beads at $\mathrm{H} / \mathrm{D}=0.5$ [5].

According to Herrera et al. [3], experimented for bubbling characteristics of fluidized bed of glass bead $(42 \mu \mathrm{m})$ and alumina $(15 \mu \mathrm{m}, 42 \mu \mathrm{m})$ in the presence of sound field, SPL $=170 \mathrm{~dB}$ and frequency $=90 \mathrm{~Hz}$. They showed experimentally that, the sound field is capable to disturb the cohesive property of nano powders and fluidization bed gets expanded homogeneously with increase in SPL till bubbling condition was observed. Above SPL $=140 \mathrm{~dB}$, at lower velocity of gas, the bed compaction characteristic of fluidized bed was observed. It was concluded that minimum bubbling velocity is directly proportional to the bed material particle size.

For mixing aeration behaviour of two nano-sized powders asAl2O3 (40nm) and $\mathrm{CuO}(33 \mathrm{~nm})$ with nitrogen as a fluidizing gas in assistance of sound field, SPL upto $140 \mathrm{~dB}$, Ammendola et al. [6] made analysis. They showed that the fluidization quality of bed with only gas fluidization is much poor than that obtained in assistance of sound field. The result were obtained on the basis of bed height and pressure drop. In presence of sound wave, as superficial velocity of gas is increased, the relative increase is shown in the bed expansion ratio $(\mathrm{H} / \mathrm{H} 0)$. Also, it was observed that, after frequency of $100 \mathrm{~Hz}$ and at $140 \mathrm{~dB}$ the pressure drop gets decreased.

Table 1 [9]: Various fluidization conditions due to presence of sound frequency.

\begin{tabular}{|l|l|}
\hline $\mathrm{f}(\mathrm{Hz})$ & Fluidization conditions \\
\hline $60-80$ & Small and medium bubbles throughout bed \\
\hline 100 & No visible bubbles \\
\hline $120-140$ & Channeling and surface spouts \\
\hline 160 & Surface spouts \\
\hline 180 & Small bubbles throughout bed \\
\hline $200-220$ & Surface spouts \\
\hline $240-340$ & Surface spouts \\
\hline $340-550$ & Deep and surface spouts \\
\hline
\end{tabular}


Effects of sound field characteristics on bubbling process in a gas fluidized bed of flyash of size $40 \mu \mathrm{m}$ withhumidified air as a fluidizing gas is analyzed by Levy et al. [10]. They have reported, the sound wave actuates the bed of material and made disturbances in order to vanish large clusters of particles formed due to intermolecular forces. In this paper, effect of sound intensity on Umf, minimum bubbling velocity and the bed pressure drop were explained. They shows the bed pressure drop reduced upto frequency $150 \mathrm{~Hz}$ after which the drop remains constant. Various fluidization conditions due to presence of sound frequency for range of 60 to $550 \mathrm{~Hz}$ were reported in paper.

The prediction of the flow characteristics of bubbling fluidized bed of the quartz sand $(74 \mu \mathrm{m})$ and $\mathrm{SiO} 2(0.5 \mu \mathrm{m})$ particles at high temperature in the presence of sound field is made by Guo et al. [11]. The experimental results were found that, Umf is decreased with frequency rise from 50 to $150 \mathrm{~Hz}$ and then increased from 150 to $400 \mathrm{~Hz}$. For bubble free process, the sound field plays an important role of breaking the large agglomerates without formation of bubble at high temperature upto $800^{\circ} \mathrm{C}$. The optimal frequency values were observed as $150 \mathrm{~Hz}$ for both $\mathrm{SiO} 2$ and quartz particles. They also concluded for the pressure fluctuations inside bed. These pressure fluctuation deviations was homogeneously reduced from 50 to $200 \mathrm{~Hz}$ and then increased from 200 to $400 \mathrm{~Hz}$.

Kaliyaperumal et al. [15] performed experiment for fluidization of sub-micron powders in the presence of sound field. It was found that, the submicron particles causes bed compaction but in case of nanoparticles, it was not found. For submicron particles, the bed expansion ration was increased with increase in the superficial velocity of gas. In the presence of sound than that was obtained in the absence. In another words, the increase in the superficial gas velocity resulted in the increase of fluidization index. It was observed upto $120 \mathrm{~Hz}$ and $120 \mathrm{~dB}$. For low gas velocity, less than $0.002 \mathrm{~m} / \mathrm{S}$, the bed compaction was observed. With subsequent increase in the frequencies, Umf was decreased upto $120 \mathrm{~Hz}$. After this, the velocity was increased and Umf was obtained for $120 \mathrm{~dB}$. Similarly, for nano powders, they have been reported that, maximum bed expansion and maximum fluidization index were at $120 \mathrm{~Hz}$ and $120 \mathrm{~dB}$ and Umf for fluidization was found at $110 \mathrm{~dB}$ [15].

Investigation for the result of the sound wave on the fluidization process of ultrafine particles as cornstarch, $\mathrm{SiO} 2$ and $\mathrm{TiO} 2$ is done by Guo et al. [16]. It was found that, for SPL $100 \mathrm{~dB}$, Umf decreases upto certain frequency. After which there is increase due to the appearance of plugging, channeling and fluidization. It is believed as sound propagates through fluidized bed, sound absorption coefficient varies directly with the square of the sound frequency. Also, maximum amount of sound energy was absorbed by the top portion of the bed and the energy was unable to reach at the bottom which caused the large clusters. It was resulted that, fluidization quality was improved by sine and triangle wave. In another words, sound waveform resulted for effective influence on the fluidization behaviours of ultra-particles.

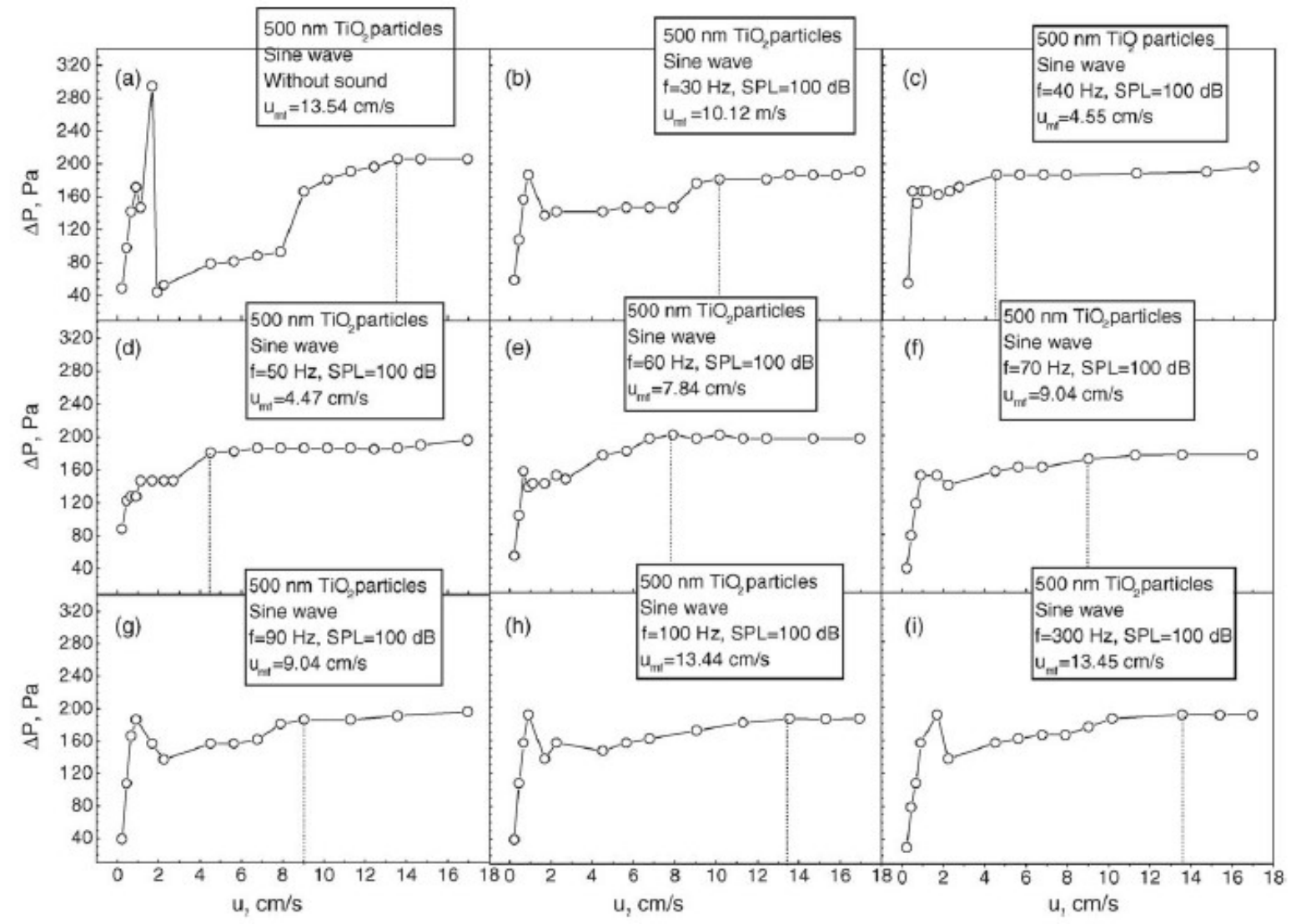

Figure 3: Effect of sound on the minimum fluidization velocity with $500 \mathrm{~nm} \mathrm{TiO} 2$ particles [16]. 
Si et al. [17] used catalytic cracking particle (FCC) of size $81.5 \mu \mathrm{m}$ for bubbling fluidized bed together with application of acoustic field. The resulted that, Umf has minimum value at frequency of $150 \mathrm{~Hz}$ and after $150 \mathrm{~Hz}$ to $500 \mathrm{~Hz}$, there was gradual increase in the Umf. Sound coefficient was increased simultaneously with increase in the frequency from 150 to $400 \mathrm{~Hz}$ at $120 \mathrm{~dB}$. They did the wavelet analysis for study of pressure fluctuations and proved as an effective tool.

$\mathrm{Xu}$ et al. [18] studied the fluidization behaviour of fine particles consisting $\mathrm{Al} 2 \mathrm{O} 3, \mathrm{TiO} 2$, glass beads and $\mathrm{FCC}$ catalysts (avg. sizes of $4.8-65 \mu \mathrm{m}$ ). It was found the assistance of sound field enhances the bed fluidization quality with more pressure drop and lower Umf. They predicted, with increase in the velocity of gas beyond a transition value, larger bed voidage was observed. It was resulted that, Umf initially decreased to certain value and then increased rapidly after particular value of frequency. The particle bed for each powder is consolidated in sound field at lower gas velocity. The effect of sound field on fluidization was mainly dependent on the SPL (intensity) value, the frequency of sound applied and the properties of particles. In addition, they also reported the group identification of C/A particles in the presence of sound field. For fluidization, the group Cparticles showed the decrease in SPL values with unvarying pitch when the gas velocity was allowed to increase. While in case of group A particles, they showed varying pitch with increase in the gas velocity.

Zhu et al. [22] experimented the sound assisted fluidization of silica nano powder of size $12 \mathrm{~nm}$ with $\mathrm{N} 2$ as a fluidizing gas. They obtained the results as, with aid of sound field, there was increase in the bed expansion with rise in superficial gas velocity and the value of SPL. They reported that, in assistance of sound field, channeling or slugging of bed quickly vanishes and the bed starts expanded consistently.

Ajbar et al. [12] also predicted the effects of sound waves for silica material with size $12 \mathrm{~nm}$, air as a fluidizing gas, SPL of $125 \mathrm{~dB}$ and the frequency range from 100 to $400 \mathrm{~Hz}$. They concluded that, as velocity of gas increases more than Umf, pressure drop decreases and the bed expands, the void fraction increases leading to decrease in the value of pressure drop. They have been reported, in case of sound assisted performance, the mean of the pressure drop is decreased as compared to no sound performance. Together with this, the addition of sand, i.e., group A powder creates more turbulence in the bed resulting a degree of bed homogeneity.

Russo et al. [14] studied the sound assisted fluidization of 0.5 to $45 \mu \mathrm{m}$ zeolite catalysts particles with various weights of powders having range from $1 \mathrm{~kg}$ to $3 \mathrm{~kg}$. For these different weights, different amount of SPL and frequencies were required for the effective breaking of clusters. When insufficient amount of sound intensity is given, it is found that only top portion of powder bed undergo fluidization whereas in lower portion, there was formation of channeling, propagating towards top portion.

Raganati et al. [13] reviewed characteristics of fluidizing bed like bed expansion, drop in bed pressure and the velocity of minimum fluidization for four various nano powders ; $\mathrm{Al} 2 \mathrm{O} 3, \mathrm{Fe} 2 \mathrm{O} 3, \mathrm{CuO}$ and $\mathrm{ZrO} 2$ with sizes less than $50 \mathrm{~nm}$ and air as a fluidizing gas. They have found consistent condition of optimum fluidization for $\mathrm{Al} 2 \mathrm{O} 3, \mathrm{CuO}$ and $\mathrm{ZrO} 2$ at particular fixed SPL value and the frequency range $100-125 \mathrm{~Hz}$ and $90-120 \mathrm{~Hz}$. With addition of some amount of $\mathrm{Fe} 2 \mathrm{O} 3$ powder to the mixture, better fluidization behaviour was observed in the bed.
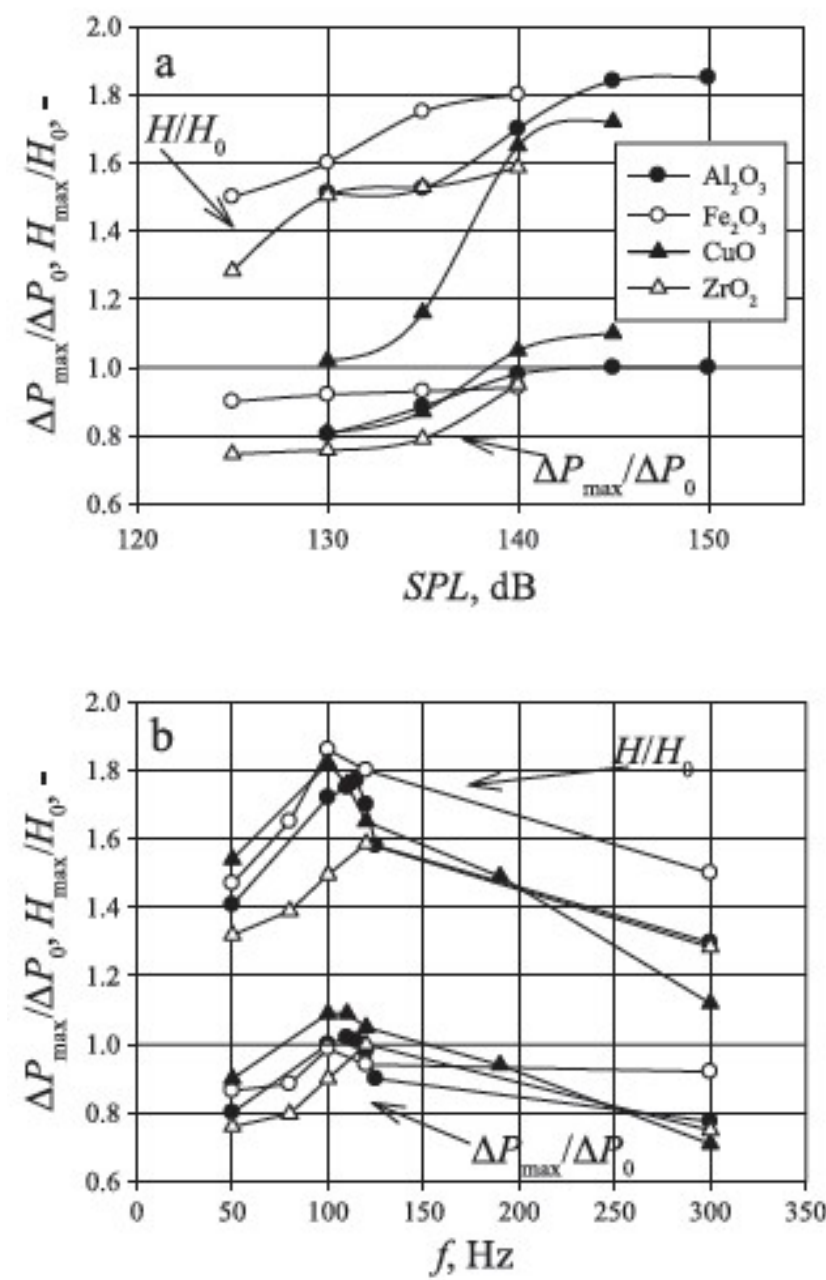

Figure 4: (a) Effect of SPL ( $=120 \mathrm{~Hz})$ and (b) effect of sound frequency $(\mathrm{SPL}=140 \mathrm{~dB})$ on

$\Delta \mathrm{Pmax} / \mathrm{P} 0, \mathrm{Hmf} / \mathrm{H} 0$ for all the powders [13].

Guo et al. [31] investigated for $\mathrm{SiO} 2$ nano particles with $7.5 \mathrm{~nm}$ and SPL of $130 \mathrm{~dB}$ and air as a fluidizing gas. They noted that, as varying orientation of the fluidizing gas flow, the shape of agglomerate is non-spherical in nature. For reduction in the value of experimental error, it is being assumed spherical. It was resulted, the frequency at which small size of agglomerate obtained, known as critical frequency. As the sound frequency is allowed to increase, the agglomerate size gets decreased upto certain frequency. After this frequency, there was increase in the size. They 
also concluded that, with the increase in the sound frequency, the sound absorption coefficient increases and large amount of waves gets absorbed by the top portion. But these waves were unable to disorient the large agglomerate at the bottom portion. Also, with respect to sound field intensity, it was observed that, for SPL values, breaking of agglomerates is carried out. In opposite of this, for large SPL, contact possibilities of particles and agglomerate gets increased and results in large size of agglomerates. It was resulted, the frequency at which small size of agglomerate obtained, known as critical frequency. As the sound frequency is allowed to increase, the agglomerate size gets decreased upto certain frequency. After this frequency, there was increase in the size. They also concluded that, with the increase in the sound frequency, the sound absorption coefficient increases and large amount of waves gets absorbed by the top portion. But these waves were unable to disorient the large agglomerate at the bottom portion. Also, with respect to sound field intensity, it was observed that, for SPL values, breaking of agglomerates is carried out. In opposite of this, for large SPL, contact possibilities of particles and agglomerate gets increased and results in large size of agglomerates.

\subsection{Heat Transfer In Fluidized Bed}

Lou et al. [9] studied the fluidization behaviour of bed and surface to bed heat transfer process. The fluidized bed material was hydrogen absorbing alloy powder $(5-15 \mu \mathrm{m})$, two types of nickel, Ni1 $(5-15 \mu \mathrm{m})$ and $\mathrm{Ni} 2(5-12 \mu \mathrm{m})$ and hydrogen, helium and nitrogen as a fluidizing gas to avoid humidification inside the bed. It was obtained that, the coefficient of heat transfer gets increased suddenly till Umf is obtained. After Umf, reduction occurs in increase in the heat transfer coefficient and the highest heat transfer coefficient was obtained for fine powder fluidized bed.

A relationship for heat transfer coefficient in fluidized bed,proposed by Hashizume et al. [8]. The fluidized bed material used were glass $(1.9-7 \mathrm{~mm})$, ceramics $(1.3-$ $8.3 \mathrm{~mm})$ and chromium $(2.4 \mathrm{~mm})$. It was observed that, heat transfer coefficient is inverse in proportion of the diameter of particle. Also the value of heat transfer coefficient are dependent on the column diameter and the diameter of the embedded tube. The correlation between these three parameters was given in the investigation as, $\mathrm{h} \alpha \mathrm{Dc}^{1 / 4}$ and $\mathrm{h}$ $\alpha \mathrm{Dt}^{1 / 4}$; where, Dc is a diameter of column, $\mathrm{Dt}$ is a diameter of embedded tube.

Wang et al. [19] explored the effects of the resistance time of particle on surface of high temperature in the fluidized bed and the heat transfer coefficient from the heating surface. The material for the fluidized bed used was magnesite $(0.85-0.35 \mathrm{~mm})$ and hollow corundum sphere $(1.10-0.87 \mathrm{~mm})$. They have been discussed all the tree types of heat transfer phenomenon in the bed during fluidization processes as conduction, convection and the radiation. They found that, the particle resistance time on the surface does not affect the convective heat transfer coefficient howeverthe total heat transfer coefficient gets decreased.Similarly, in case of surface temperature of the heating element, conductive and radiative heat transfer component gets decreased and conductive heat transfer component remains nearly unvarying. Further they reported an increase in $(\mathrm{U} / \mathrm{Umf})$ causes a small variation in the convective heat transfer component where conductive and radiative components also gets increased. Total heat transfer coefficient gets reduced with increase in the diameter of heating element. The conduction component gets increased and other both, convective and the radiative heat transfer coefficient gets reduced.

Ma et al. [20] predicted the heat transfer phenomenon for circulating fluidized bed of FCC particles $(67 \mu \mathrm{m})$ and the immersed surface. The different heat transfer coefficient distribution at different axial position are experimented. It was found from the graph that, at center portion, the concentration of the solid particles are much less and unvarying. Due to this, large velocity gas carries these particles to upward. At the opposite hand, this gas velocity is less and hence large size clusters were observed at the wall side portion. So, the distribution of the heat transfer coefficient were resulted as low and much uniform in the central portion than at the wall. Similarly, in case of increase in the bed height, heat transfer coefficient does not get affected more at central portion but at annular portion, heat transfer coefficient starts reducing.

Hilal et al. [23] made study on the relationship between the fluidizing velocities during heat transfer in fluidizing velocity. The analysis was done for four different bed materials as glass ballotini, diakon, nickel shot and lead shot. The experimental results were obtained as for maximum heat transfer condition, (U/Umf) ratio is allowed to decrease with rise in the length of heat transfer zone and in the distance of heat source from the distributer plate and this distance for maximum heat transfer coefficient was found as $0.12 \mathrm{~m}$. Also, it was found that the increase in the particle diameter of materials, glass, diakon and nickel, the maximum value of heat transfer coefficient was observed for small values of (U/Umf).

Grewal et al. [24] done an experimental work of investigation of heat transfer phenomenon in fluidized bed of the different materials with electrically heated horizontal tube. The materials used were silicon, carbide, alumina, silica, dolomite, glass beads and lead glass with air as a fluidizing gas through compressor. The experimental results were found as, when the mass of fluidizing velocity rises from 0.2 to $0.8 \mathrm{~kg} / \mathrm{m}^{2} \mathrm{~S}$, average heat transfer coefficient rises upto about $0.5 \mathrm{~kg} / \mathrm{m}^{2} \mathrm{~S}$ and then reduces gradually. This was done on the basis of the particle mode of heat transfer involving resistance time of the particle on the surface and the particle density close to the surface. They have been observed that the bed height of material and tube material, both, does not affect the heat transfer coefficient. This coefficient gets decreased with diameter of the tube due to rise in the solid particle temperature.

Wey et al. [26] explored the fluidization behaviour and heat transfer characteristics in babbling fluidized bed of sand 
with additives of $\mathrm{Al} 2 \mathrm{O} 3$ and $\mathrm{BiO} 2$. They found that, when there was a generation of bubbles in the fluidized bed, the heat transfer rises suddenly with gas velocity and obtained a maximum heat transfer coefficient. They made comparison of $\mathrm{SiO} 2$ and $\mathrm{A} 12 \mathrm{O} 3$ materials on the basis of density and heat capacity for better heat transfer rate. These thermal properties have much effect on the on the heat transfer in fluidization. So, it was concluded that the addition of high density particles with large size increases the contact frequency between heating surface and the bed material helps for enhancement of heat transfer coefficient.

Kim et al. [27] done experimentation for heat transfer in silica sand $(240 \mu \mathrm{m})$ particle bed at different angular positions of the heating element. It was reported that, with rise in surficial velocity of gas, local heat transfer coefficient rises because of increase in replacement of particle pockets at the tube surface.

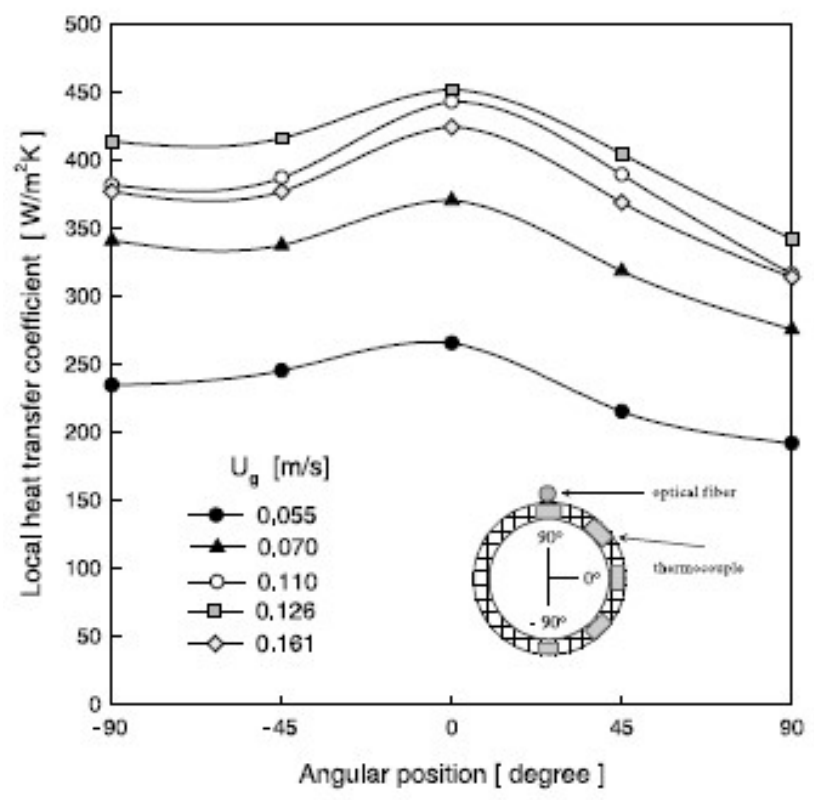

Figure 5: The local time-averagedcoefficient of heattransferfor angular positions at different gas velocity [27].

Changes in thecoefficient of heat transfer on the type of tube was small and hence it was obtained that, the solid particles were less affected by the bubbles. The coefficient of heat transfer is contrariwiserelated to the resistance time of particle on tube surface with more bubbling frequency.

\subsection{Heat Transfer In Fluidized Bed With Application Of Sound Field}

Wankhede et al. [4] experimented the heat transfer process for different gas velocities, sound field conditions and the various angular positions of the heating surface. Glass beads $(462 \mu \mathrm{m})$ and clay $(112 \mu \mathrm{m})$ were used for fluidizing bed material with air as a fluidizing gas. The information about the selection of Theinformation about the selection of acoustic frequency for maximum acoustic energy competence was explored. With increase in the frequencies, there was a particular frequency at which the SPL obtained as maximum and this maximum SPL effectively work for fluidization process. They found for both materials that, the lowering of surface temperature at angular position of $90^{\circ}$ due to the rapid replacement of fresh particles at the surface.

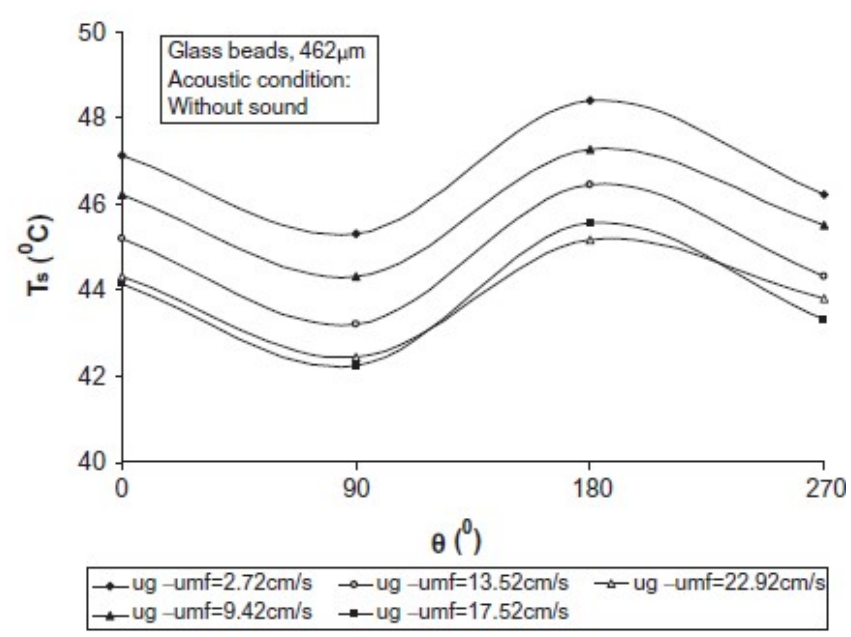

Figure 6: Surface temperature vs angular position around circumferenceof the tube for glass beads, $462 \mu \mathrm{m}$, without sound [4].

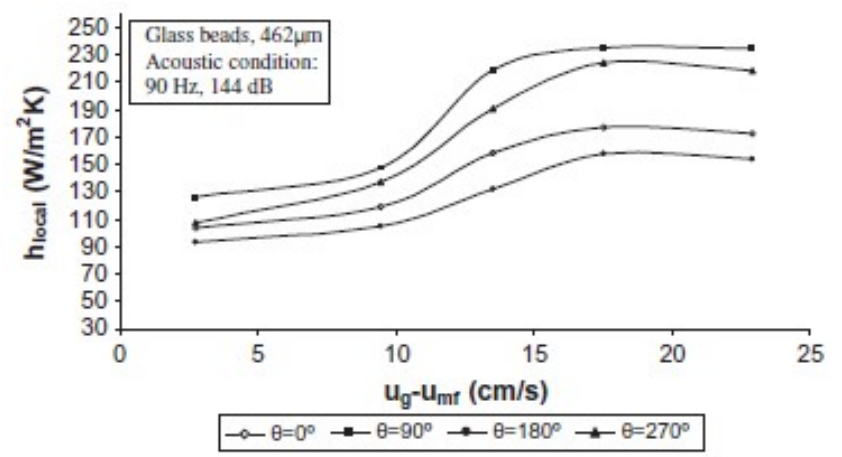

Figure 7: Coefficients of local heat transfer vs velocity of excess air (ug - umf) at various values of $\mathrm{h}$ for glass beads, $462 \mu \mathrm{m}, 144 \mathrm{~dB}[4]$.

With increase in the gas velocity, the particle replacement was obtained faster and hence, heat transfer coefficient increases rapidly with excess gas. It was observed that, with subsequent increase in the value of SPL beyond $140 \mathrm{~dB}$, the heat transfer coefficient starts reducing as less contact time of the particle to the heating surface occurred and the particle were unable to conduct the heat from heating surface inside the bed.

Huang et al. [21] investigated the bubble behaviour and heat transfer coefficient in fluidized bed of Geldart A, B, C materials as glass beads, fly ash HC, fly ash SH, fly ash BW and talc with horizontal heating tube in the presence of sound field. They predicted the increase in the average heat transfer coefficient as excess gas velocity rises together with rise in the values of SPL. 


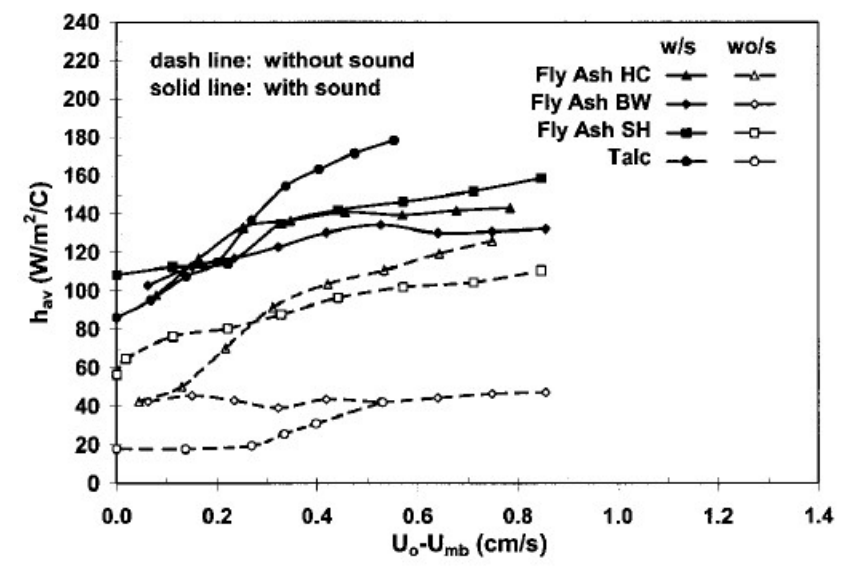

Figure 8: Variation of coefficients of average heat-transfer with velocity of excess air [21].

More heat transfer rate was obtained at angular positions at more the movement of particles. At the top region of bed, movement was less and also the heat transfer rate. Geldart A and $\mathrm{B}$ type powders were found as easy to fluidize without sound but for Geldart C powders, sound field was essential for having fluidization property. It was found that, with increase in the SPL from $124 \mathrm{~dB}$ to $144 \mathrm{~dB}$ and with increase in the excess gas velocity, bubbling frequency increased and hence, heat transfer coefficient also was increased.

\section{CONCLUSIONS}

Nano powders have unique property of large surface area per unit mass and very small particle size which is necessary in worldwide industrial processes. For having these processes in effective manner, it is importatnt to separate the particles of the nano powder. Gas fluidiztion is the conventional technique for seperating. As discussed previously, gas- solid fluidizing bed gives the results like, high heat and mass transfer rates, the quality to deal various types of the particle properties, the quality of being suitable for the large scale operation and unvarying and controllable temperatures of the bed.

Conferring to the literauture appraised, in case of nano powders, they have much inter-molecular forces that can not be removed with conventional gas fluidization. To overcome this problem and to obtain better fluidization quality, sound assisting method plays an important role. With addition of the sound field of the different intensities and the frequencies to gas fluidization process, breaking of the large agglomerates, movement of particles occur together with bed expansion, reduction in minimum fluidization velocity of the gas, improvement in the degree of mixing andsmooth fluidization gives result for the effective heat tranfer rate in the fluidized bed of nanopowders.

The future scope regarding this review, will be the investigation of minimum fluidization velocity, bed expansion ratio, bed pressure drop, heat transfer coefficient at different angular positions for various nano powders in absence and presence of different sound pressure level and frequencies. In presence of sound field, effective replacement of nano powders will be possible and therefore, outcome will be achieved as increase in heat transfer coefficient from heating rod to bed material.

\section{REFERENCES}

[1] Jaber shahabanian, Rouzbeh Jafari, Jamal Chaouki, "Fluidization of Ultrafine Powders", International Reiew of chemical engineering, Vol. 4, 2012.

[2] J. Ruud van Ommen, Jose Manuel Valverde, Robert Pfeffer, "Fluidization of nanopowders: a review", J Nanopart Res(2012) at Springerlink.com.

[3] E.K. Levy, C.A. Herrera, "Bubbling characteristics of sound assisted fluidized beds", Powder Technology 119, pp. 229-240,2001.

[4] U.S. Wankhede, R.L. Sonolikar, S.B.Thombre, "Effect of acoustic field of heat transfer in a sound assisted fluidized bed of fine powders", International Journal of Multiphase Flow 37, pp. 1227-1234, 2011.

[5] David R. Escuderot and Theodore J. Heindel, "Acoustic field effect on minimum fluidization velocity in a $3 \mathrm{D}$ fluidized bed", Proceedings of the ASME 2012, Fluids Engineering Summer Meeting, FEDSM2012, July 2012.

[6] P. Ammendola, R. Chirone, "Aeration and mixing behaviours of nano-sized powders under sound vibration", Powder Technology 201, pp. 49-56,2010.

[7] S. Kaliyaperumal, S. Barghi, J. Zhu, L. Briens, S. Rohani, "Effect of acoustic vibration on nano and submicron powders fluidization", Powder Technology 210 (2011) pp. 143-149.

[8] K. Hashizume, "An approach to develop a correlation for liquid-fluidized bed heat transfer", Chemical Engineering and Processing 45, pp. 990-1000,2006.

[9] Chun-Hua Luo, Hiroyuki Hamano, Shigeyuki Uemiya, Toshinori Kojima, "Fluidization and surface to bed heat transfer coefficient in fluidized beds of very fine $\mathrm{Ni}$ and $\mathrm{Ni}$ alloy powders", Journalof Chemical Engineering of Japan, Vol. 31, No.1, pp. 95-102, 1998.

[10] Edward K. Levy, Ilan Shanitzer, Toru Masaki, John Salmento, "Effect of an acoustic field on bubbling in a gas fluidized bed", Powder Technology 90, pp. 53-57, 1997.

[11] Qingjie Guo, Jian Zhang, Junyi Hao, "Flow characteristics in an acoustic bubbling fluidized bed at high temperature", Chemical Engineering and Processing 50 (2011) pp. $331-337$.

[12] Ajbar, Y. Bakhbakhi, S. Ali, M. Asif, "Fluidization of nano-powders: Effect of sound vibration and premixing with group A particles", Powder Technology 206 (2011) pp. 327337.

[13] Federica Rangati, Paol Ammendola and Riccardo Chirone, "Role of acoustic fields in promoting the gas-solid contact in a fluidized bed of fine particles", KONA Powder and Particle Journal; Reiew paper.

[14] P. Russo, R.Chirone, L. Massimilla, S. Russo, " The influence of the frequency of acoustic waves on soundassisted fluidization of beds of fine particles", Powder Technology 82 (1995) pp. 219-230.

[15] Qingjie Guo, Huie Liu, Wenzhong Shen, Xianghong Yan, Rugao Jia, "Influence of sound wave characteristics on 
fluidization behaviours of ultrafine particles", Chemical Engineering Journal 119 (2006) pp. 1-9.

[16] Chongdian Si, Jing Zhou, Qingjie Guo, "Characterization of pressure fluctuation signals in an acoustic bubbling fluidized bed", Journal of the Taiwan Institute of Chemical Engineers 42 (2011) pp. 929-936.

[17] Chunbao Xu,Yi Cheng, Jesse Zhu, "Fluidization of fine particles in a sound field and identification of groups C/A particles using acoustic waves", Powder Technology 161 (2006) pp. 227-234.

[18] Li Wang, PingWu, Jing Yang, Xuezhi Ni, "Modelling of heat transfer between a high temperature fluidized bed and an immersed surface by a surface-particle-emulsion model", Chemical Engineering Science 62 (2007) pp. 503512.

[19] Y. Ma, J-X, Zhu, "Heat transfer between gas-solid suspension and immersed surface in an upflow fluidized bed (riser)", Chemical Engineering Science 55 (2000) pp. 981989.

[20] DeShau Huang and Edward Levy, "Heat transfer to fine powders in a bubbling fluidized bed with sound assistance", American Institute of Chemical Engineers, AIChE Journal, Vol.50, No. 2.

[21] Chao Zhu, Guangliang Liu, Qun Yu, Robert Pfeffer, Rajesh N. Dave, Caroline H. Nam, "Sound assisted fluidization of nanoparticle agglomerates", Powder Technology, 141 (2004) pp. 119-123.

[22] N. Hilal, M. A. Hastaoghu, M.C. Leaper and S.W. Kingman, "The relationship between particle properties and fluidizing velocity during fluidized bed heat transfer", Advanced Powder Technology, Vol. 15, No. 5, (2005) pp. 583-594.

[23] N. S. Grewal, S.C. Saxena, "Heat transfer between a horizontal tube and a gas-solid fluidized bed", International Journal of Heat Mass Transfer, Vol. 23,pp. 1505-1519.

[24] Nima Masoumifard, Navid Mostoufi, Ali-Asghar Hamidi, Rahmat Sotudeh-Gharebagh,"Investigation of heat transfer between a horizontal tube and a gas-solid fluidized bed", International Journal of Heat and Fluid Flow 29, pp. 1504-1511, 2008.

[25] Ming-Yen Wey, Chiou-Liang Lin andShr-Da You, "Fluidized behaviour and heattransfer in a bubbling fluidized bedincinerator", Journal of Environmental

Engineering and Management 17 (3), pp. 169-175,2007.

[26] Sung Won Kim, Jung Yeul Ahn, Sang Done Kim, Dong Hyun Lee, "Heat transfer and bubble characteristics in a fluidized bed with immersed horizontal tube bundle", International Journal of Heat and Mass Transfer 46 (2003) pp. 399-409.

[27] Balasim A. Abid, Jamal M. Ali, Ayar A. Alzubaidi, “ Heat transfer in a gas-solid fluidized bed with vaious heater inclinations", International Journal of Heat and mass transfer 54 (2004), pp. 2228-2233. 